Article

\title{
Simulation Study of Dynamic Bus Lane Concept
}

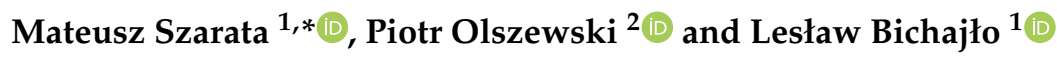 \\ 1 The Faculty of Civil and Environmental Engineering and Architecture, Rzeszow University of Technology, \\ 35-959 Rzeszów, Poland; leszbich@prz.edu.pl \\ 2 Faculty of Civil Engineering, Warsaw University of Technology, 00-637 Warsaw, Poland; \\ p.olszewski@il.pw.edu.pl \\ * Correspondence: matsza@prz.edu.pl
}

check for updates

Citation: Szarata, M.; Olszewski, P.; Bichajło, L. Simulation Study of Dynamic Bus Lane Concept. Sustainability 2021, 13, 1302. https:// doi.org/10.3390/su13031302

Academic Editor: Marianna Jacyna Received: 30 November 2020

Accepted: 20 January 2021

Published: 27 January 2021

Publisher's Note: MDPI stays neutral with regard to jurisdictional claims in published maps and institutional affiliations.

Copyright: () 2021 by the authors. Licensee MDPI, Basel, Switzerland. This article is an open access article distributed under the terms and conditions of the Creative Commons Attribution (CC BY) license (https:// creativecommons.org/licenses/by/ $4.0 /)$.

\begin{abstract}
Not many publications are available on using microsimulation models to analyze the feasibility of implementing the dynamic bus lane (DBL) concept. The paper presents the methodology and calibration process used for DBL modeling. For the selected four sites in Rzeszów (Poland), three options were analyzed: no bus lane, standard exclusive bus lane (XBL), and dynamic bus lane. The analyses were carried out using PTV Vissim software with an additional logic script to control the DBL activation. Simulation model parameters were calibrated using a genetic algorithm. The final assessment of individual options was based on the weighted average travel time for all transport modes. The results show that the dynamic bus lane could bring the same benefits to public transport and cause only a slight increase in travel times in private transport compared to XBL. The XBL solution, depending on the site, led to increasing the average travel time in private transport by $12 \%$ to $25 \%$, while the dynamic bus lane increased by $1 \%$ to $12 \%$. Weighted average travel time per person is proposed as the overall indicator of efficiency. Preliminary analyses show that the bus volume, bus occupancy, routing, and traffic conditions will affect the efficiency of the new solution.
\end{abstract}

Keywords: dynamic bus lanes; transport modelling; public transport

\section{Introduction}

Bus service is an essential and, in many cities, the only element of the public transport system. Improving the quality and attractiveness of bus services has been identified as one of the key strategies toward sustainable mobility [1]. That is why it is important for such service to work efficiently and to constitute an appealing alternative to private transport. As a result, city authorities worldwide have been increasingly introducing different forms of traffic priority, including bus lanes, to the most crowded streets. Implementing a separate bus lane requires consideration of the available road space as well as both passenger and traffic volumes. The traffic characteristics of many streets may not justify introducing exclusive bus lanes (XBL) that are operating all day. In that case, it is possible to introduce XBLs that are operating only at peak hours. An example of such an approach may be seen in Rzeszow (Poland), where the local transport authority decided to introduce XBLs only during the morning and afternoon rush hours.

Nowadays, there is also another possibility to improve the bus service. A modern ICT technology, known as Intelligent Transport Systems (ITS), gives engineers new opportunities to prioritize buses. Since 2015, Rzeszów city has been equipped with modern ITS infrastructure and has joined the group of the most modern cities in Poland in terms of ITS implementation. It is also one of the few cities in which the ITS system operates throughout the city. That is why the city transport authority has considered the introduction of a new concept for XBL-separated dynamic bus lanes (DBLs). In this solution, all the road users may benefit from a DBL because the time delay incurred by individual car drivers is minimized and the benefits for the public transport may be the same as in the case of the standard bus lane. Due to its advantages, the DBL could be used on more street sections, 
which would increase the attractiveness of the bus service. The most interesting implementations of the DBL system took place in Lisbon in 2006 [2] and in Lyon in 2017 [3]. In both cases, the DBL operation was monitored and revealed benefits in the form of reducing the bus travel times on the designated sections by $25 \%$ in Lisbon and $15 \%$ in Lyon.

Although there were very few practical implementations, the DBL concept has been the subject of many research studies that have shown its potential benefits. In several studies, the authors used microsimulation traffic models to check the potential advantages of a new XBL solution and compare it with the standard bus lanes [4,5]. For example, the advantages are reduction of congestion and travel times for private vehicles and better utilization of the available road space. Moreover, a study by Wu et al. [5] compared the DBL strategy with Transit Signal Priority (TSP) and focused on the efficiency that can be achieved with these solutions. One of the results of this study was that the DBL and TSP benefits depended on the cycle length of traffic lights. DBL benefits seems to get smaller as the red duration gets longer. The implementation of TSP together with DBL can lead to bus travel time savings that are larger than the sum of time savings of the two individual strategies. Chiabaut et al. obtained similar conclusions in article [6], where DBL and TSP strategies were analyzed using a kinematic wave model. The model predicts that the starting a DBL triggers a capacity reduction at the first traffic signal and increases the bus travel time. DBL strategies associated with TSP reduce both travel times of buses and travel time variability. In another study [7], the authors used a microsimulation model developed in AIMSUN software to examine the benefits and limitations of the dynamic bus lane. The authors proposed using bus speed, traffic flow, and intersection delays to evaluate the effectiveness of a DBL. It was found that the speed of buses (both for DBL and XBL) remained almost constant when the traffic flow was up to $0.7-0.75$ of capacity. When the traffic was heavy (more than 0.75 of capacity), bus speeds decreased, even by about $20 \%$, in comparison with the standard bus lane. In a study by Liu et al. [8], a cell transmission model proposed by Eichler and Daganzo [9] was used to compare the efficiency of XBLs and DBLs in terms of the network effects. The results show that DBLs can distribute the priority of bus lanes more flexibly to buses and hence can improve the system performance to a larger degree than XBLs. The Swedish report [10] focused on a wider analysis of DBL introduction, considering the legal issues, the impact on traffic safety, and the possibility of applying this solution. In paper [11], the authors evaluated the operational effects of DBLs under the Connected Vehicles environment. They obtained conditions for the deployment of DBLs in terms of bus headway and traffic density. Very interesting analyses were made for Thessaloniki in Greece, where this new form of bus lane has been evaluated for the potential benefit of reducing air pollution [12].

It seems that the success of DBLs depends largely on the correct identification of street segments where this solution can bring the most benefits. However, at present, there are no methods or specific guidelines on how to identify such locations and traffic conditions. This task can be achieved with microsimulation models. The problem is that presently available microsimulation software does not have a built-in module to perform the DBL analyses. However, the Vissim software has some functions that help to conduct a full simulation of the DBL operation. One of them is the possibility to change model settings while the simulation is running. An example of such an application is given in article [13], where the authors introduced Variable Speed Limit strategy in the Vissim model to improve the management of non-recurrent congestion.

The general objective of the current study is to demonstrate the potential benefits of the DBL as compared to the standard XBL using the traffic microsimulation approach. Specific research objectives could be stated as follows:

- To develop and calibrate a microsimulation traffic model suitable for analyzing streets with signalized intersections and an operating DBL scheme,

- To develop a control module within the simulation model that would emulate DBL operation,

- To identify specific traffic conditions where a DBL would be most suitable. 
The article presents a method of estimating the potential benefits of a DBL using microsimulation models and analysis. Special attention is given to model calibration using the genetic algorithm (GA) approach. Microsimulation models with different DBL control strategies are described.

\section{Subject of the Study and Traffic Surveys}

Rzeszów is the largest city in southeastern Poland. The public transport is based mainly on the bus network. In 2015, the city implemented an ITS traffic management system, together with a number of improvements in the functioning of public transport, including exclusive bus lanes. A proposal to enhance the system with DBL in several locations is under study.

In order to compare the efficiency of the DBL and XBL, traffic surveys were carried out on selected streets of Rzeszow. Four street sections with similar lengths (about $700 \mathrm{~m}$ ) were selected for the study (Hetmańska Street, Podkarpacka Street, Okulicki Avenue and Dabrowski Street). All street sections consist of two traffic lanes in each direction and have similar but not the same traffic conditions as well as the daily number of buses passing through. The initial selection of street sections was made with the help of the literature [14-16].

The scope of traffic surveys conducted during the afternoon peak hour (3:30-4:30 PM) included the observations of traffic volume, traffic composition, turning volumes at intersections, as well as measurement of travel times of both public and private transport. During the peak hour, traffic volumes varied from $680 \mathrm{veh} / \mathrm{h}$ (at Hetmańska Street) to 1190 $\mathrm{veh} / \mathrm{h}$ (at Okulicki Avenue), and the number of buses ranged from $10 \mathrm{bus} / \mathrm{h}$ (at Okulicki Avenue) to 27 bus/h (at Dabrowski Street). Only at one section, Dabrowski Street, the common XBL is currently operating. Results of the traffic survey are shown in Table 1.

Table 1. Traffic survey results—afternoon peak hour.

\begin{tabular}{|c|c|c|c|c|c|}
\hline Street & $\begin{array}{l}\text { Peak Hour Traffic } \\
\text { Flow [veh/h] }\end{array}$ & $\begin{array}{l}\text { Peak Hour Bus } \\
\text { Flow }[\text { bus } / \mathrm{h}]\end{array}$ & $\begin{array}{l}\text { Buses as Flow } \\
\text { Percentage [\%] }\end{array}$ & $\begin{array}{l}\text { Bus Occupancy } \\
\text { [person/bus] }\end{array}$ & XBL \\
\hline Okulicki Avenue & 1190 & 10 & 0.8 & 37 & No \\
\hline Podkarpacka Street & 1093 & 13 & 1.2 & 37 & No \\
\hline Dąbrowski Street & 870 & 27 & 3.1 & 38 & Yes \\
\hline Hetmańska Street & 680 & 19 & 2.8 & 41 & No \\
\hline
\end{tabular}

\section{DBL Operating Principle and Infrastructure}

It is assumed that the DBL operates in two modes: an active mode or a stand-by mode. In the stand-by mode, the DBL system remains deactivated, and vehicles may use all traffic lanes. DBL is activated only when a bus approaches the designated road section where traffic conditions are unfavorable. The dynamic bus lane system consists of vehicle detectors and variable message signs (VMS), which inform drivers when the dynamic bus lane is excluded from general use. Information about the active mode is being sent to drivers also by in-pavement LED lights, which are located at the edge of the traffic lane. The marking and signage scheme of the DBL is shown in Figure 1.

One of the most important rules is that when the DBL system is being activated, vehicles already present on the street section may continue to drive along the lane. Only vehicles approaching the street section with a DBL should switch lanes and use only the remaining available lanes. In this way, the bus lane is cleared in preparation for a bus arrival.

The modern ICT technology, which is currently present in many cities, gives the possibility to manage and control the DBL system. It is only necessary to expand the existing infrastructure with an additional module for bus detection and for informing drivers about the current status of the DBL. One of the activation criteria may be associated with traffic conditions, which is why it will be necessary to upgrade the detection system 
also with traffic condition assessment. An additional activation criterion could be associated with the number of passengers. In Table 2, a summary of DBL infrastructure elements is presented.

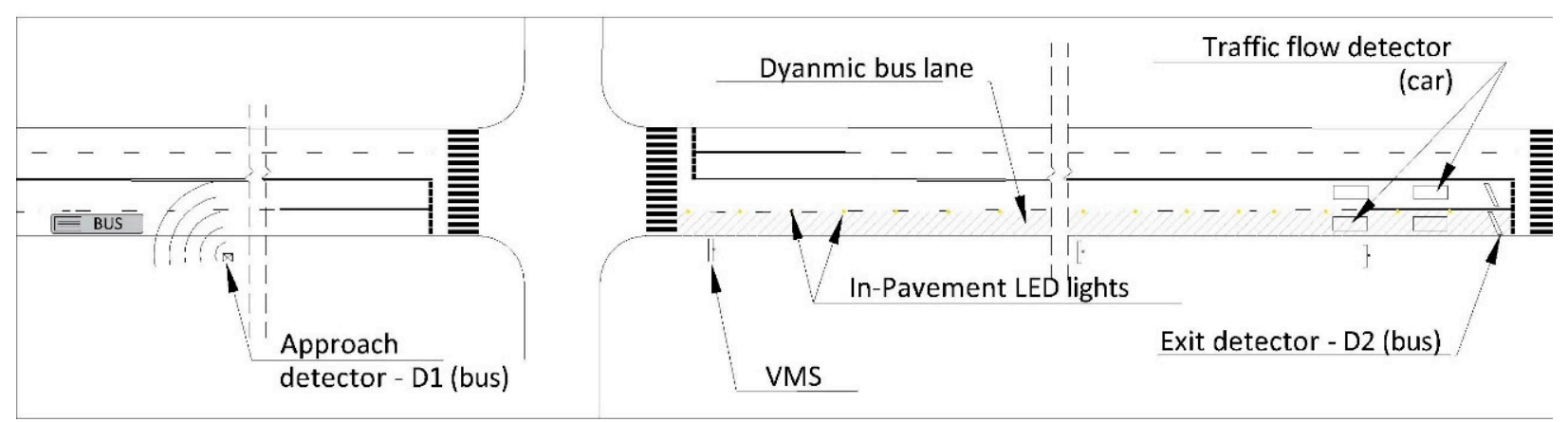

Figure 1. Marking and signage scheme of the dynamic bus lane (DBL).

Table 2. Summary of DBL infrastructure elements.

\begin{tabular}{lll}
\hline \multicolumn{1}{c}{ Devices on Buses } & \multicolumn{1}{c}{ Road Infrastructure } & \multicolumn{1}{c}{ Information Sent to the Controller } \\
\hline - Vehicle locating devices, e.g., via GPS, & - DBL controller & - Bus coordinates \\
long-range radio transmitters & - Variable message signs & - Traffic conditions \\
- Passenger counting devices & - LED lights in pavement & - Current state of traffic light controller \\
& - Traffic detectors (e.g., induction loops, & - Number of bus passengers \\
& video detection) & \\
\hline
\end{tabular}

Another solution that is being tested is V2V (vehicle-to-vehicle) and V2I (vehicleto-infrastructure) communication enabling direct information exchange between private vehicles and public transport. The use of this form of communication for informing drivers about the active state of DBL was tested in 2009 as part of the CVIS (Cooperative Vehicle Infrastructure Systems) program in Bologna [17].

\section{Microsimulation Traffic Modelling and Calibration}

The completed traffic surveys made it possible to acquire the most important data and parameters necessary for microsimulation traffic models. The models were developed using the PTV Vissim program [18]. The first stage of building a traffic model requires inputting data about the existing road system to the computer. Basing on a detailed city map, the geometry of streets and intersections was created, taking into account the width and number of lanes and radii of curves. In the next stage, the traffic management data were introduced into the model. At this stage, it was necessary to set priority rules for intersections (in the case of intersections without traffic lights) or to implement the traffic lights control program. In the next step, data from the traffic survey (traffic volume, composition, and vehicle routes) were input. Public transport was also included at this stage. Bus lines and their routings were defined, including dwell times at bus stops. During the traffic surveys, it was observed that some vehicles were moving along the bus lanes in an unauthorized way. For this reason, a special group of vehicles was introduced in the computer model to represent unauthorized users of bus lanes.

The last stage of the study was to calibrate and validate the simulation process, considering the local traffic characteristics and adapting the model to each location separately. For the calibration of microsimulation traffic models, the Wiedemann 74 model was selected. Based on literature review [18-20], a group of the seven most important parameters and ranges of their possible values was selected (Table 3). 
Table 3. Parameters included in the calibration process.

\begin{tabular}{|c|c|c|c|c|c|}
\hline $\mathrm{Nr}$ & Parameter & $\begin{array}{l}\overline{0} \\
\text { हे } \\
\text { के }\end{array}$ & $\begin{array}{l}\frac{0}{\pi} \\
\frac{\Xi}{\pi} \\
\Sigma\end{array}$ & 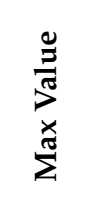 & 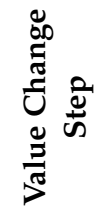 \\
\hline 1 & $\begin{array}{l}\text { PrT Desired Speed Distribution-uninterrupted speed of private } \\
\text { vehicles; is assigned to vehicles using stochastic distributions }[\mathrm{km} / \mathrm{h}]\end{array}$ & $X 1$ & 60 & 80 & 10 \\
\hline 2 & $\begin{array}{l}\text { PuT Desired Speed Distribution - uninterrupted speed of public } \\
\text { transport; is assigned to vehicles using stochastic distributions }[\mathrm{km} / \mathrm{h}]\end{array}$ & $X 2$ & 50 & 60 & 10 \\
\hline 3 & $\begin{array}{l}\text { Number of Observed Preceding Vehicles-affects how well drivers can } \\
\text { predict other vehicles' movements and react accordingly [veh] }\end{array}$ & X3 & 1 & 4 & 1 \\
\hline 4 & $\begin{array}{l}\text { Average Standstill Distance-average desired distance between } \\
\text { stopped cars [m] }\end{array}$ & $X 4$ & 1 & 3 & 0.5 \\
\hline 5 & $\begin{array}{l}\text { Waiting Time before Diffusion-maximum time a vehicle can wait for a } \\
\text { gap to change lanes, after that it is taken out of the simulation [s] }\end{array}$ & $X 5$ & 15 & 60 & 15 \\
\hline 6 & $\begin{array}{l}\text { Minimum Headway-minimum distance to the vehicle in front that } \\
\text { must be available for a lane change in standstill condition [m] }\end{array}$ & $X 6$ & 0.5 & 6.5 & 1 \\
\hline 7 & Safety Distance Reduction Factor-factor reducing safety distance [-] & $X 7$ & 0.05 & 0.65 & 0.1 \\
\hline
\end{tabular}

\section{Application of a Genetic Algorithm}

The parameter ranges and their value change steps adopted allow generating 17,640 unique parameter value combinations. To speed up the calibration process, it was decided to use a genetic algorithm (GA). One of the biggest advantages of this method is the versatility of applications, which means that it can be used in many fields of science [21-23]. GA is characterized by conducting the search for the best combination of parameter values, starting not from a single point but from an adopted space of solutions, using probabilistic rules of solution selection. Recommendations for the use of GA have been proposed by the Virginia Department of Transportation, USA, in guidelines on the calibration of microsimulation models developed in Vissim and CorSim programs [24,25]. The use of genetic algorithms in the calibration process in PTV Vissim is helped by the Component Object Model (COM) port [26], which enables communication between the PTV Vissim and an external program (e.g., MatLab). This makes it possible to develop a special script to run and control the algorithm. The procedure of finding the correct combination of parameters using GA requires a number of steps (Figure 2). The procedure was implemented in MatLab.

In the initial step of the procedure, one needs to set the size of the population of randomly generated solutions (chromosomes). Each chromosome is made up of a specific combination of genes (parameters used in calibration of the model) (Figure 3).

A unique combination of genes will be randomly drawn for each chromosome. The size of the population should depend on the number of parameters being optimized. A population that is too small can cause the algorithm to get stuck in the local minimum; on the other hand, a large population unnecessarily prolongs the calculation process [27], especially when each chromosome should be tested in Vissim. For this step, it was decided to draw a population consisting of seven chromosomes. The generated population of chromosomes is entered into the microsimulation program. Chromosomes are coded with integer numbers (e.g., gene A can take the value of $1=60,2=50$ or $3=60$ ), which allows significantly reducing the space in which the algorithm will move (about 17,000 combinations). This approach allows optimizing the algorithm's working time, because testing each chromosome in a microsimulation program may take up to several minutes. Furthermore, traffic simulation with each chromosome is run several times with changing values of the random seed variable. 


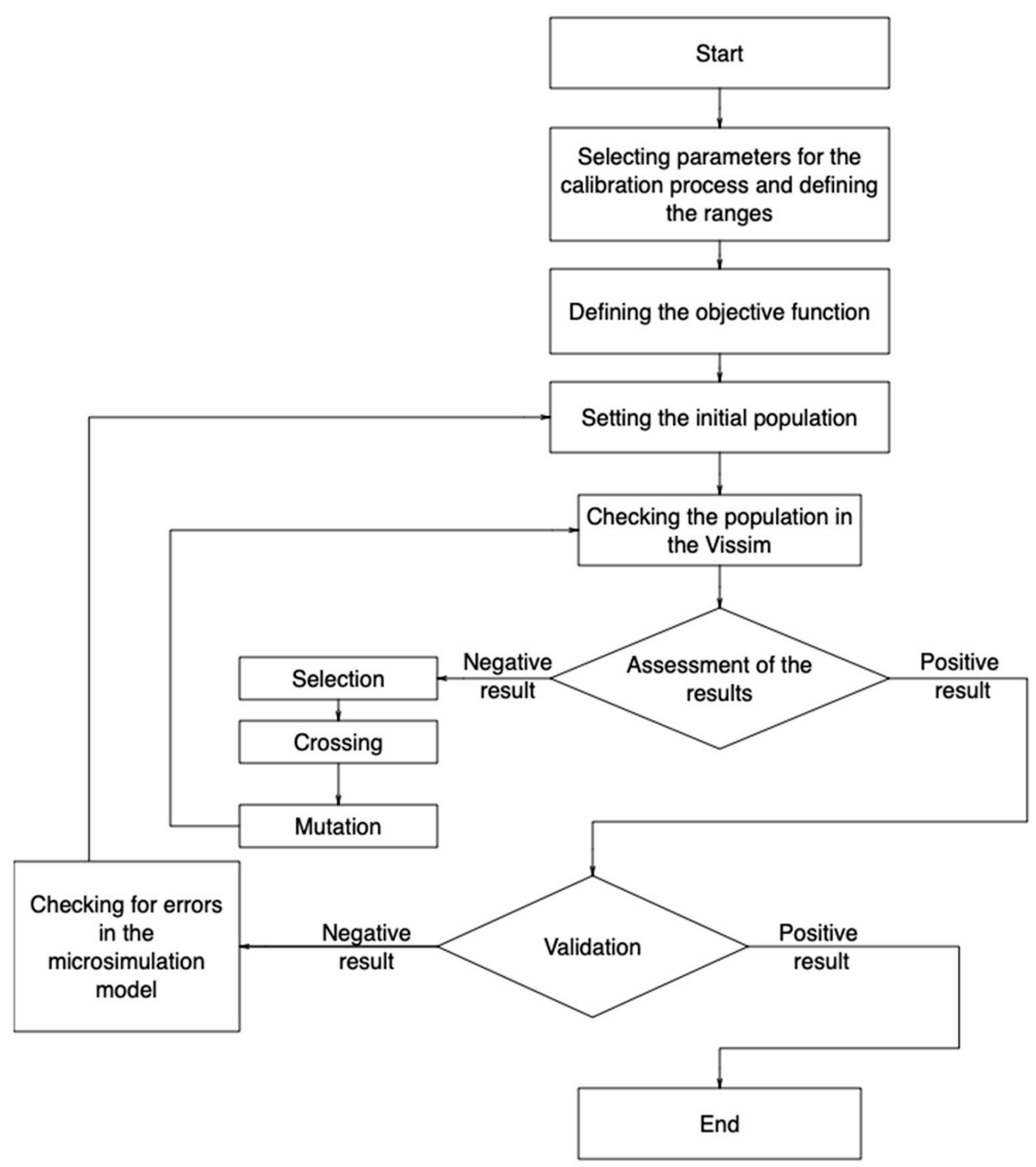

Figure 2. Genetic algorithm (GA)-based model calibration procedure.
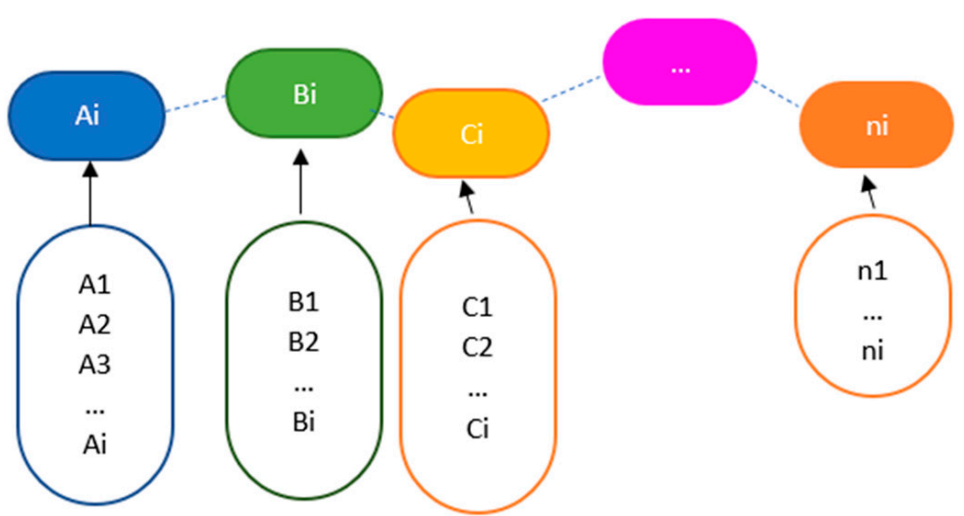

Figure 3. Structure of a chromosome. 
Based on the results obtained, the algorithm performs the process of pre-selection, during which individual chromosomes are evaluated and ordered according to their fitness. The pre-selection process can be carried out using different methods. Since the chromosome elements must consist of integer numbers, it was decided to choose a stochastic method. The stochastic selection method lays out a line in which each chromosome corresponds to a section of the line of length proportional to its scaled value. The algorithm moves along the line in steps of equal size, thus selecting the chromosomes that will participate in the reproduction process as parents.

In the next step, the crossover reproduction process begins, which is considered a key stage of the algorithm. It allows keeping the best values of individual parameters. The method of crossover depends on the chromosomal coding adopted in the algorithm. For integer numbers, the single point crossover method was chosen, which selects a part of random length from the first parent chromosome and a complimentary part from the second parent chromosome in order to create a child chromosome. The last stage in creating a new chromosome is the mutation, which introduces random changes in parameter values for the chromosomes created during the crossover stage. The mutation allows introducing new "genetic material" and protects the algorithm from getting stuck in the local minimum point. In the literature [28], one can find suggested mutation proportions in the range from $1 \%$ to $5 \%$ of the entire chromosome population.

In order to assess the fitness of individual chromosomes (parameter value combinations) based on traffic simulation runs, it is necessary to define the objective function that will be minimized:

$$
y(\min )=\frac{\left|\bar{t}^{P r T}-\bar{t}_{\text {sim }}^{\text {PrT }}\right|}{\bar{t}^{P r T}}+\frac{\left|\bar{t}^{\text {PuT }}-\bar{t}_{\text {sim }}^{\text {PuT }}\right|}{\bar{t}^{P u T}}
$$

where

$\bar{t}^{P r T}$-average travel time of private transport determined from traffic survey,

$\bar{t}^{P u T}$ _average travel time of public transport determined from traffic survey,

$\bar{t}_{s i m}^{P u T}$-average travel time of public transport obtained from the simulation,

$\bar{t}_{s i m}^{P r T}$-average travel time of private transport obtained from the simulation.

The combinations of parameter values generated in this way for the selected street sections were tested in the microsimulation program. The traffic and bus volumes presented in Table 1 were used to simulate the peak hour conditions. To evaluate the calibrated simulation models, travel times (for PuT, PrT) and traffic volumes were compared with the survey results. Differences in mean travel times were below $9 \%$ for PuT and $8 \%$ for PrT, which is well within the $15 \%$ normally expected [29] to prove a good fit of the model. Comparison of average values and standard deviations of travel times-obtained from traffic survey and simulation model — is presented graphically in Figure 4. Model standard deviation values are generally lower but of the same order as those from the survey.

GEH statistic was used to check the match between the modeled and observed traffic volumes. A GEH value of less than 5.0 is considered a good agreement [30]. The best traffic volume match was found for Okulicki Avenue $(\mathrm{GEH}=0.8)$, and the highest GEH value (but still within the limit) was obtained for Podkarpacka Street $(\mathrm{GEH}=2.1$ ). 


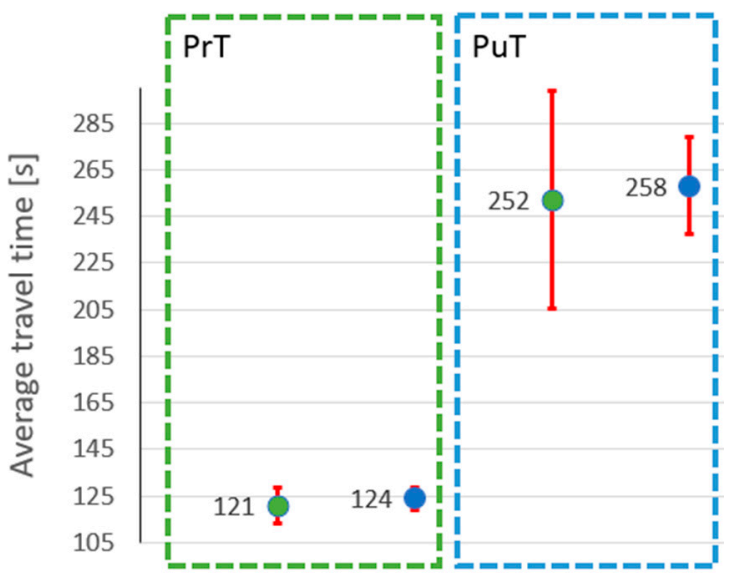

(a)

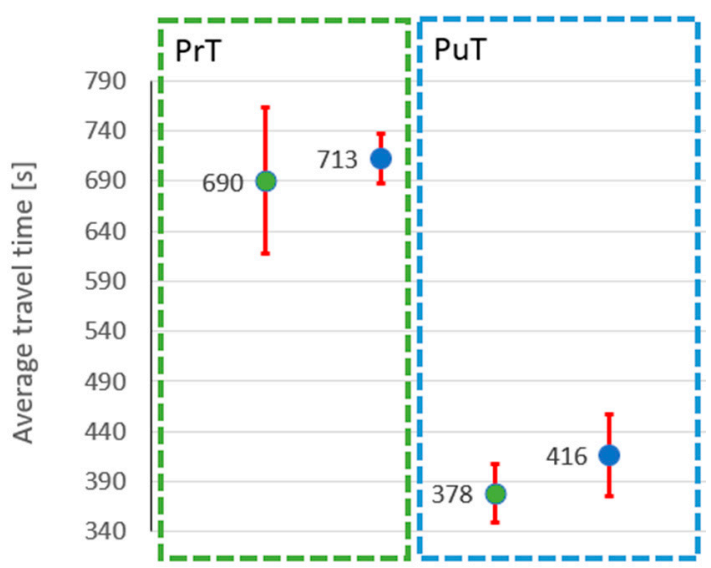

(b)

- Average travel time - Traffic survey

- Average travel time - Model

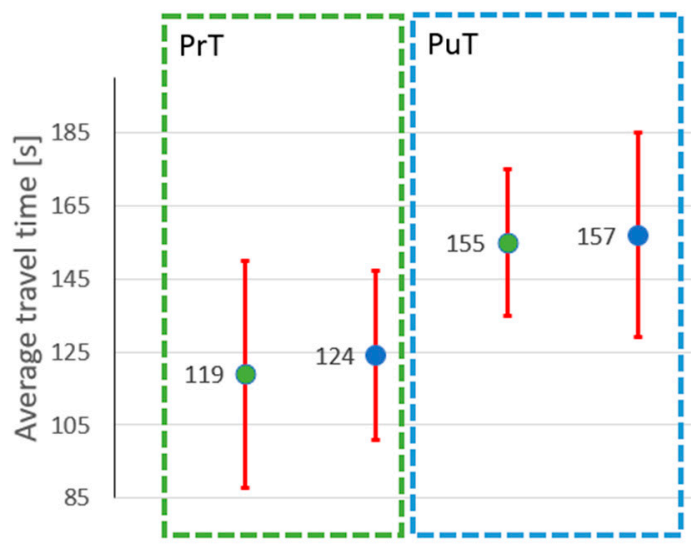

(c)

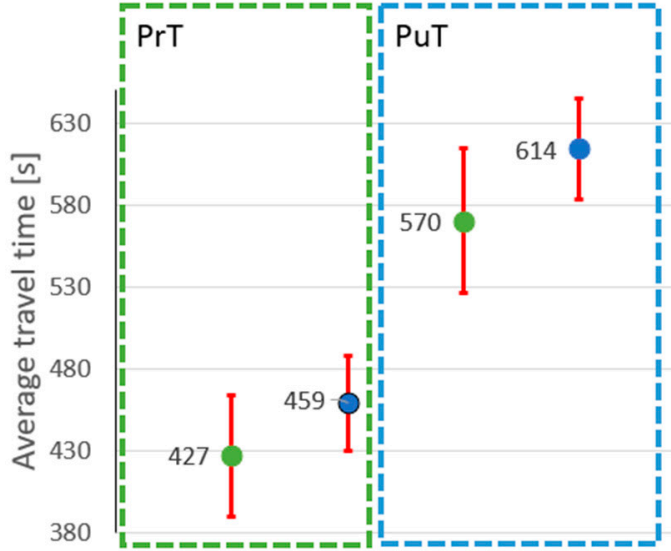

(d)

Figure 4. The average travel times and standard deviations for tested streets: (a) Okulicki Ave., (b) Podkarpacka St., (c) Dabrowski St., and (d) Hetmańska St.

\section{Options Analyzed}

The traffic models developed enabled the analysis of the separated bus lanes during the peak hour in the following configurations:

- Option 1 represents the state with no separate bus lanes,

- Option 2 represents the traffic conditions after introducing exclusive bus lanes,

- Option 3 represents the DBL solution.

To prepare the dynamic bus lane option, it is necessary to introduce additional detection points in the model, which will make it possible to detect the bus and locate it along the street section being considered. The location of the first detection point (D1-see Figure 1) was determined using an additional parameter " $T c^{\prime}$ ", i.e., the total time spent for activating the bus lane. It is defined by the equation:

$$
T_{c}=t_{o p}+t_{R t}
$$

where

$T_{c}$-total lane activation time necessary for a single bus to pass [s],

$t_{o p}$-time necessary to clear vehicles from the activated bus lane [s],

$t_{R t}$-bus travel time [s]. 
The last point of the detection system is located at the end of the priority section (D2). The adopted DBL basic control strategy (Figure 5) assumes that the system will be activated every time when a bus is approaching the priority section and deactivated when the bus passes the exit detector (D2), unless another approaching bus has been detected in the meantime. Thus, the system is being deactivated when the numbers of buses counted at each detection point $\left(\mathrm{N}^{\mathrm{D} 1} ; \mathrm{N}^{\mathrm{D} 2}\right)$ are the same. This condition is true when the last bus detected has left the section. The adopted control logic was implemented in the traffic model using Vis/VAP module in PTV Vissim software.

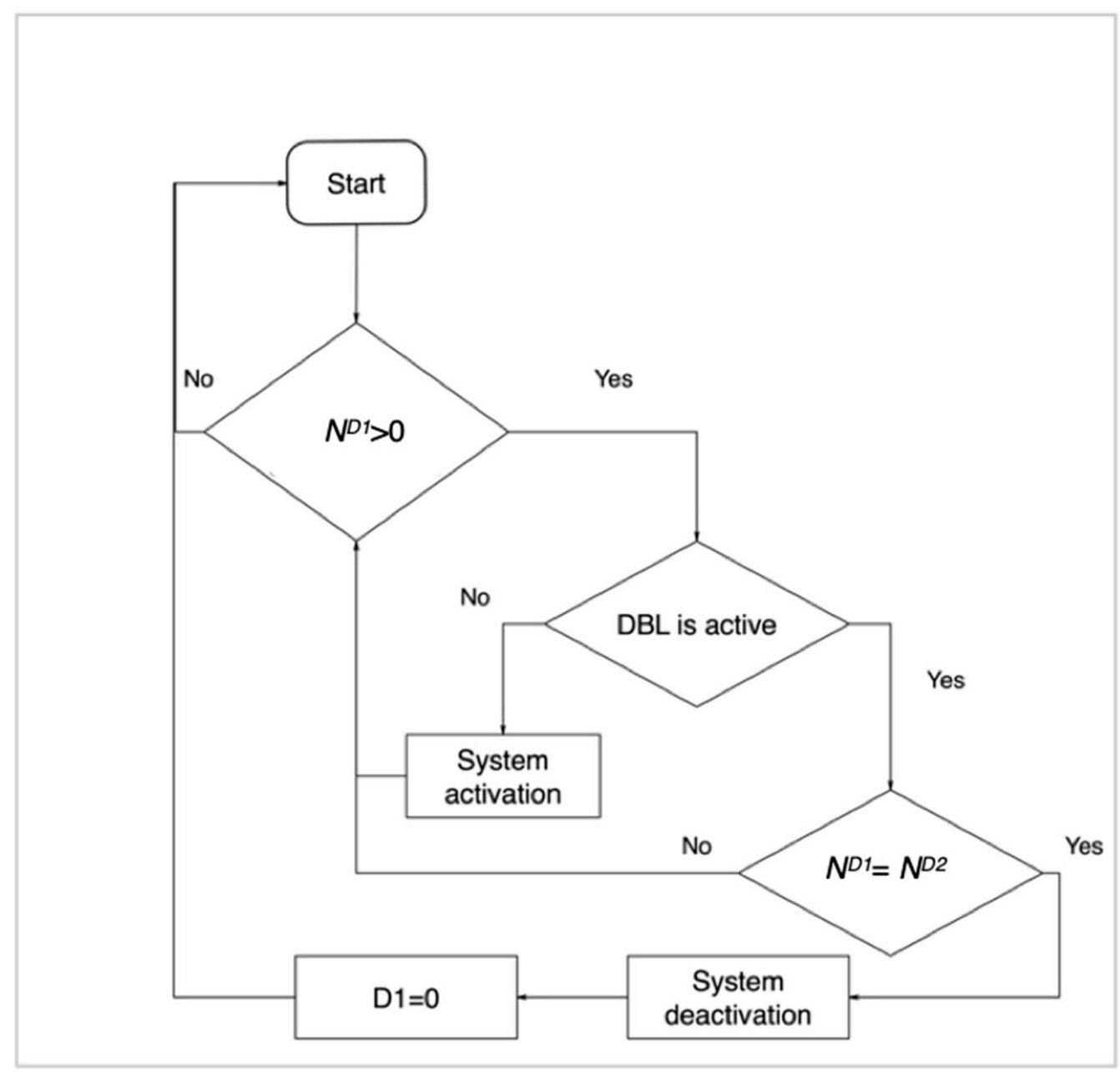

Figure 5. DBL control logic.

A more advanced possible control strategy that makes activation dependent on the current traffic conditions was described by the authors in another article [30]. An additional necessary condition for the activation was the traffic queue length at the intersection approach being longer than the maximum queue that could be discharged in one cycle. Similar criteria were suggested in other recent publications [31,32]. Figure 6a presents situations in which the bus lane is not needed. Figure $6 \mathrm{~b}$ shows an early stage of DBL activation, when approaching vehicles are directed to the remaining lane. In Figure $6 \mathrm{c}$, the DBL is almost ready for the bus arrival. 


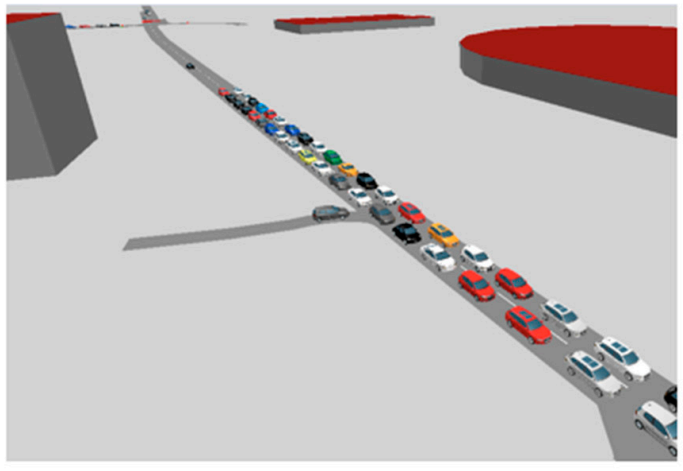

(a)

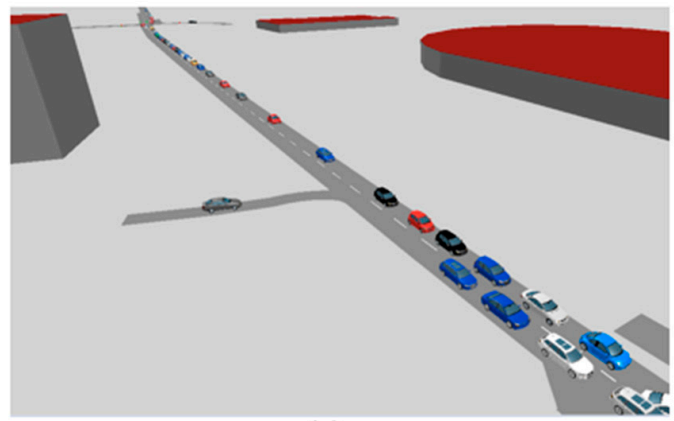

(c)

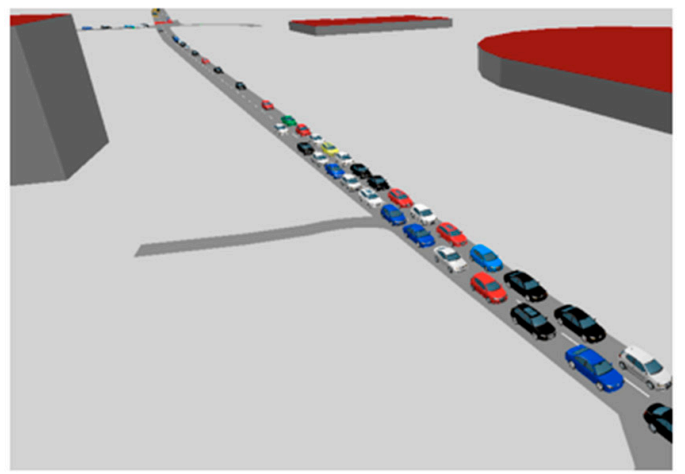

(b)

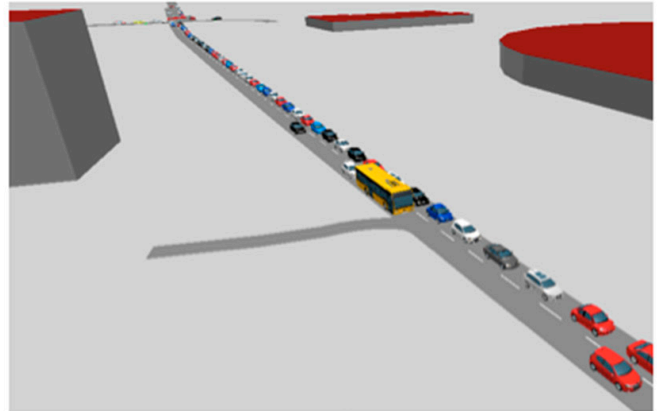

(d)

Figure 6. Simulation of dynamic bus lane activation: (a) inactive lane, $(\mathbf{b}, \mathbf{c})$ lane activation stage, (d) passage along a separate bus lane.

\section{The Simulation Results}

The assessment of individual options was based on average travel times by public and private transport through the street section under consideration (Figures 7-10). The final results for each option were obtained by conducting multiple simulations, which allowed to reflect the stochastic nature of vehicle traffic. At Okulicki Avenue, introducing priority for buses reduced the bus travel time by $14 \%$. In case of private vehicles, the travel time increased by $22 \%$ under the XBL option and by $8 \%$ when the bus lane operated as a DBL. At Okulicki Avenue, the average DBL active operating time was 22 min per hour, which gave the priority passage for eight buses. The details are shown in Figure 7.

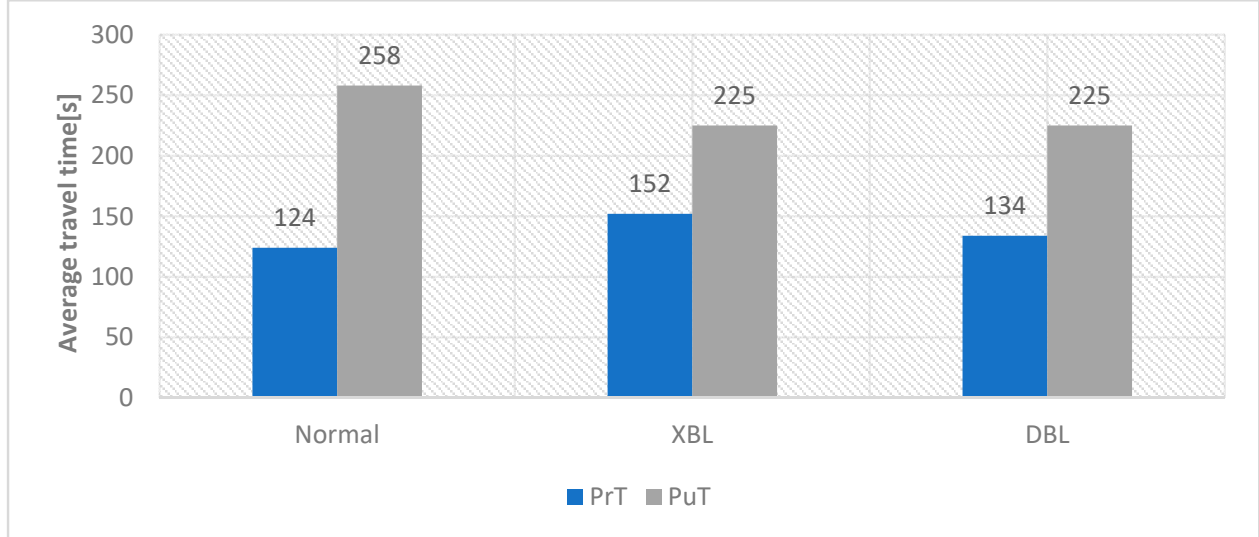

Figure 7. Summary of average travel times at Okulicki Avenue for private transport (PrT) and public transport (PuT). 


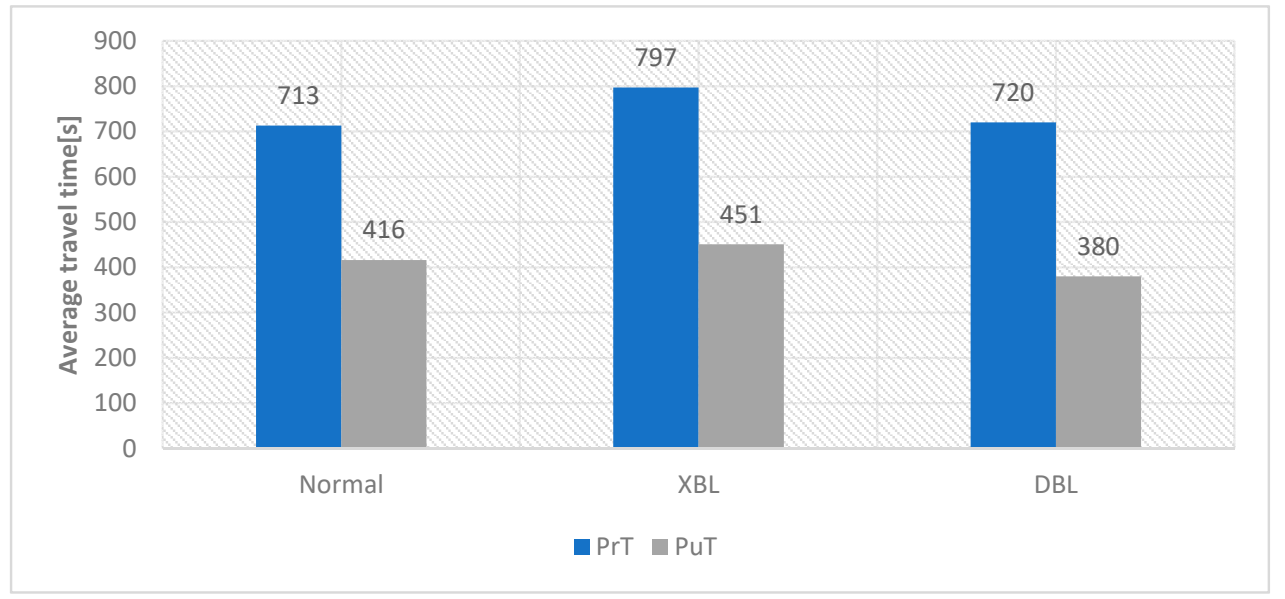

Figure 8. Summary of average travel times at Podkarpacka Street for private transport (PrT) and public transport (PuT).

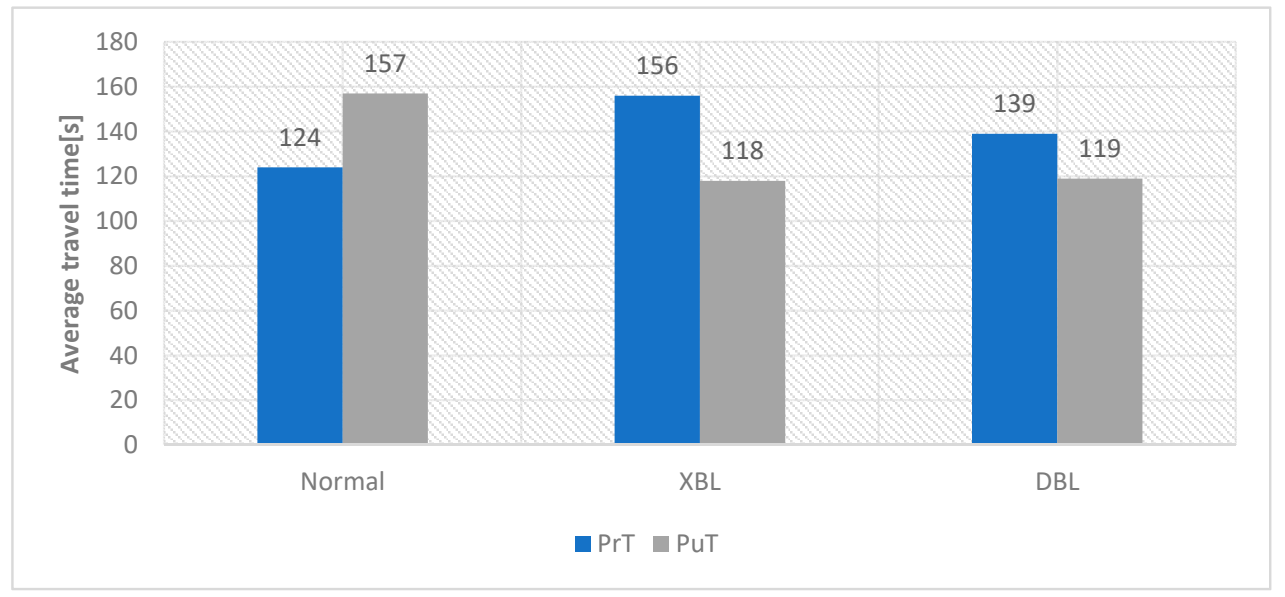

Figure 9. Summary of average travel times at Dabrowski Street for private transport (PrT) and public transport (PuT).

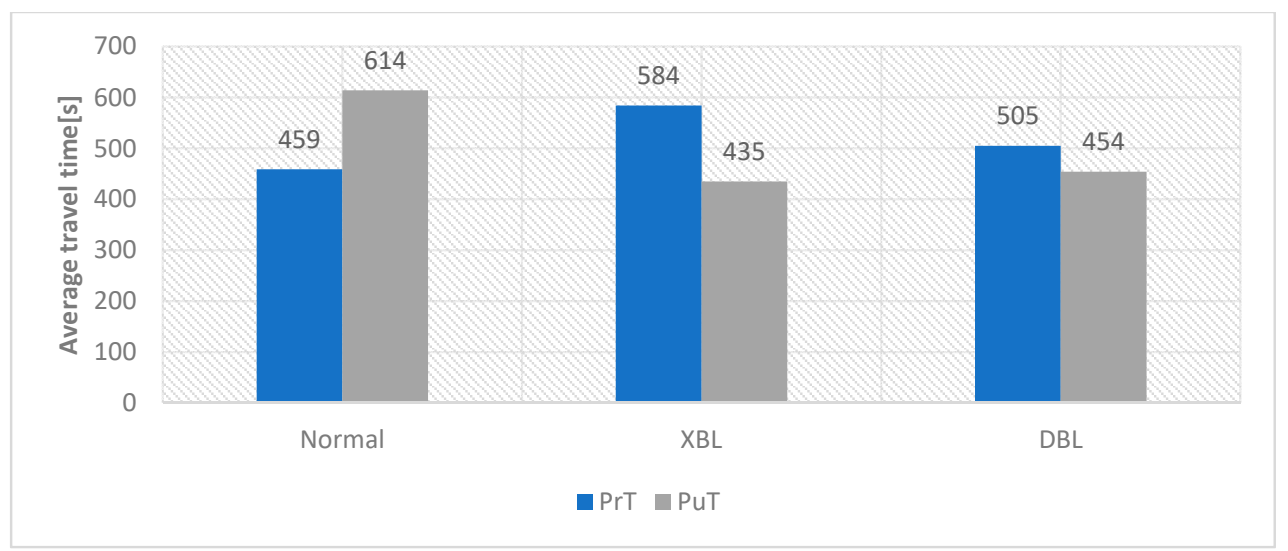

Figure 10. Summary of average travel times at Hetmańska Street for private transport (PrT) and public transport (PuT).

At Podkarpacka Street, introducing XBL resulted in an unexpected $8 \%$ increase in the travel time for public transport (Figure 8). This was because bus lane introduction caused a significant deterioration of traffic conditions at the initial street segment, which was used 
by most of the buses entering this street. Such a phenomenon was not observed under the DBL option, where the bus travel time was shortened by about $9 \%$. At the same time, this solution contributed to only a slight increase in travel time for private transport. On average, 10 buses were given priority at Podkarpacka Street, and the DBL system has been active for $31 \mathrm{~min}$ per hour.

At Dabrowski Street, where the separated bus lane is already operating, the priority allowed saving $33 \%$ of the time for public transport on average. The introduction of a DBL allowed for saving more than $13 \%$ of travel time for private transport on average (Figure 9). In this case, the DBL needed to be active for approximately 45 min to give priority passage for 27 buses during the peak hour.

Introducing bus lanes to the last site at Hetmańska Street allowed saving $35-41 \%$ of travel time for public transport (Figure 10). Despite the large number of buses, again, the largest time increase for private transport (over $27 \%$ ) was observed under the standard bus lane option. The DBL option resulted in an increase by $10 \%$ in the average travel time for private transport. The average activation time to give priority passage for 19 buses amounted to 34 min per hour.

In order to find an overall indicator of the transport efficiency of different options, the weighted average travel time (WATT) values were calculated for the private and public transport modes combined. These weighted average values (Equation (3)) for all the sites and all the options are presented in Table 4.

$$
W A T T=\frac{t_{P r T} Q_{P r T} N_{P r T}+t_{P u T} Q_{P u T} N_{P u T}}{Q_{P r T} N_{P r T}+Q_{P u T} N_{P u T}}
$$

where

WATT—weighted average travel time per person [s],

$t_{P r T}$-average travel time for private transport [s],

$Q_{P r T}$ - traffic flow of private transport vehicles (see Table 1) [veh/h],

$N_{P r T}$-average occupancy of private vehicles, equal to 1.2 [person/veh],

$t_{P u T}$-average travel time for public transport [s],

$Q_{P u T}$-traffic flow of buses (see Table 1) [veh/h],

$N_{P u T}$-average occupancy of buses (Table 1) [person/veh],

Table 4 also shows the percentage change in average travel time, which corresponds to the change of the total "system travel time" (in person-hours) under each bus lane option with reference to the normal option (no bus lane). We can see that at the first two sites, introducing XBL increases the system average travel time by over $10 \%$, while the DBL option makes very little difference compared to "no bus lane" option. However, at the last two sites, there is some improvement in WATT under XBL and much bigger improvement under DBL.

Table 4. Weighted average travel times (WATT) per person-all modes combined.

\begin{tabular}{cccccc}
\hline \multirow{2}{*}{ Street } & Normal & \multicolumn{2}{c}{ XBL } & \multicolumn{2}{c}{ DBL } \\
\cline { 2 - 6 } & [s/person] & [s/person] & \% change & [s/person] & \% change \\
\hline Okulicki Avenue & 151.6 & 167.0 & $10.2 \%$ & 152.7 & $0.8 \%$ \\
Podkarpacka Street & 633.3 & 704.2 & $11.2 \%$ & 628.8 & $-0.7 \%$ \\
Dabrowski Street & 140.4 & 137.2 & $-2.3 \%$ & 129.1 & $-8.0 \%$ \\
Hetmańska Street & 534.7 & 511.2 & $-4.4 \%$ & 480.1 & $-10.2 \%$ \\
\hline
\end{tabular}

\section{Discussion}

The study has demonstrated that properly calibrated traffic microsimulation models can be used to evaluate the feasibility of using the dynamic bus lanes on specific segments of urban streets. A special control module has to be included in the model to allow for the correct simulation of DBL activation, deactivation, and operation. The proposed genetic 
algorithm method of model calibration for specific sites has proven to be efficient-it generated optimum values of the seven key Vissim model parameters. The calibrated models showed reasonably good agreement with observed values of both traffic volumes and travel times.

Simulated travel times by both private and public transport were used to evaluate the efficiency of different bus lane options (no lane, XBL, DBL) at different sites. Weighted average travel time is proposed as the overall indicator of efficiency. In general, when an exclusive bus lane is introduced, public transport private users gain and private transport users lose in terms of travel time reduction. The WATT indicator shows the overall effect on travel time, considering both traffic and bus volumes as well as the vehicle occupancy of both modes. A priority scheme can be considered feasible if WATT is reduced when compared to the "no bus lane" option. The results (Table 4) show that in all cases, DBL results in smaller WATT than XBL, and at three sites, there is an overall reduction in travel time. A significant reduction of the weighted average travel time is shown at Dabrowski Street $(8 \%)$ and Hetmańska Street $(10 \%)$ - these are locations where the bus flows are between 19 and 27 buses/h and constitute about $3 \%$ of the total traffic (Table 1). Based on the cases considered, these seem to be the conditions that favor implementation of the DBL scheme.

The simulations show that the DBL solution generates a shorter traffic queue than that created under the standard bus lane option, which in some cases may have a key impact on the decision to introduce this form of priority. An example of this phenomenon may be observed on the section of Podkarpacka Street, where the standard bus lane generated a large traffic queue at the beginning street segment, which is used by most buses. As a result, the average bus travel time, instead of becoming shorter as expected, became significantly longer.

As the results presented are based on a limited number of traffic simulation runs, the conclusions should be viewed with some caution. There are further limitations of the approach presented-for example, only peak hours were analyzed. The balance of effects on private and public transport users may be different during off-peak hours. However, using the traffic-dependent activation strategy should overcome this problem: in low traffic conditions, the DBL will be activated less often, thus improving conditions for private transport. Another limitation is the fact that the unauthorized use of the active bus lane by private vehicles has not been considered in the simulation. If such phenomenon is frequent, it may reduce the potential benefits of DBL.

The current research can be extended in several aspects in the future. In addition to overcoming the limitations mentioned above, there are plans to perform sensitivity analysis in order to check the effect on WATT of varying traffic and bus volume as well as bus occupancy. Another aspect to check is the effect of allowing taxis to use DBLs. In the end, the decision to implement a DBL should be based on a comprehensive economic feasibility analysis. A simplified economic analysis method was proposed by the authors in another publication [33]. It would be beneficial to include in such analysis the environmental effects of DBL, such as fuel consumption, air pollution, etc.

\section{Summary}

Dynamic bus lanes are a new alternative to the standard XBL solutions. The dynamic bus lane gives the same benefits to public transport as the standard bus lane option. In addition, according to traffic simulation, the DBL option causes only a slight increase in travel time for private transport. The XBL solution, depending on the section, led to increasing the average travel time for private transport by $12 \%$ to $25 \%$, while the dynamic bus lane increased it only by $1 \%$ to $12 \%$.

The analysis of the possibility of introducing the DBL in Rzeszów has shown the great potential of this form of priority, which can also be used in other cities in Poland. Microsimulation traffic models were used to carry out the analyses. The study shows that the new solution allows considerably limiting the average travel time increase for 
private transport, which is associated with the introduction of standard bus lanes. Smaller travel time increases are beneficial for traffic on the main route, which in some cases may significantly affect the passage times of buses trying to join traffic from a minor street approach. Based on the cases analyzed, the DBL system may bring benefits for the bus flows of 19 to 27 buses per hour. The number of buses is significant but another important parameter affecting the efficiency of the DBL scheme is the total time of activation, which may be influenced by traffic conditions at the intersection.

There are important policy implications of the study-it seems that the DBL scheme may be feasible in locations where standard XBL is not. As DBLs can reduce the travel times by bus, it should be beneficial to public transport passengers and make buses more attractive. At the same time, it can also be more acceptable to private transport users, as it increases their travel time less than XBL and eliminates the perception of "empty bus lanes" that nobody can use.

Author Contributions: Conceptualization, M.S., P.O. and L.B.; methodology, M.S., P.O.; software, M.S.; validation, M.S., P.O.; formal analysis, M.S., P.O.; investigation, M.S., P.O. and L.B.; data curation, M.S., P.O.; writing—original draft preparation, M.S., L.B.; writing-review and editing, M.S., P.O.; visualization, M.S. All authors have read and agreed to the published version of the manuscript.

Funding: This research received no external funding.

Institutional Review Board Statement: Not applicable.

Informed Consent Statement: Not applicable.

Data Availability Statement: Not applicable.

Conflicts of Interest: The authors declare no conflict of interest.

\section{References}

1. Fernandez-Sanchez, G.; Fernandez-Heredia, A. Strategic Thinking for Sustainability: A Review of 10 Strategies for Sustainable Mobility by Bus for Cities. Sustainability 2018, 10, 4282. [CrossRef]

2. Viegas, J.M.; Roque, R.; Lu, B.; Vieira, J. The Intermittent Bus lane System. In Proceedings of the 86th Transportation Research Board Annual Meeting, Washington, DC, USA, 21-25 January 2007.

3. Chiabaut, N.; Barcet, A. Demonstration and evaluation of an intermittent bus lane strategy. Public Transp. 2019, 11, 443-456. [CrossRef]

4. Lu, X.; Yu, J.; Pan, S. Locating continuous exclusive bus lanes: A corridor-based optimization model. In Proceedings of the TRB 2017 Annual Meeting, Wahington, DC, USA, 8-12 January 2017.

5. $\mathrm{Wu}, \mathrm{K}$; Lu, M.; Guler, S.I. Modeling and optimizing bus transit priority along an arterial: A moving bottleneck approach. Transp. Res. Part C 2020, 121. [CrossRef]

6. Chiabaut, N.; Xie, X.; Leclercq, L. Road Capacity and Travel Times with Bus Lanes and Intermittent Priority Activation: Analytical Investigations. Transp. Res. Rec. 2012, 2315, 182-190. [CrossRef]

7. Zyranov, V.; Mironchuk, A. Simulation Study of Intermittent Bus Lane and Bus Signal Priority Strategy. Procedia Soc. Behav. Sci. 2012, 48, 1464-1471. [CrossRef]

8. Liu, H.; Wang, J.; Ma, X. Allocating Exclusive and Intermittent Bus Lanes in Dynamic Traffic Networks. Preprints 2019. [CrossRef]

9. Eichler, M.; Daganzo, C.F. Bus lanes with intermittent priority: Strategy formulae and an evaluation. Transp. Res. Part B Methodol. 2006, 40, 731-744. [CrossRef]

10. Anund, A.; Olstam, J.; Hall, C.; Smith, G.; Habibovic, A. Dynamic bus lanes in Sweden-A pre-study. PROVDYK-Final report. 2015. Available online: https://www.k2centrum.se/sites/default/files/fields/field_uppladdad_rapport/dynamic_bus_lanes_ in_sweden.pdf (accessed on 1 January 2021).

11. Deng, W.; Song, Y.; Wang, J.; Kong, D. Evaluating Operational Effects of Bus Lane with Intermittent Priority under Connected Vehicle Environments. Discret. Dyn. Nat. Soc. 2017, 2017. [CrossRef]

12. Kampouri, A.; Politis, I. Optimization of a bus lane with intermittent priority dynamically activated by the road traffic. In Proceedings of the 23rd International Transport and Air Pollution Conference, Thessaloniki, Greece, 15-17 May 2019.

13. Farrag, S.; Youssef El-Hansali, M.; Yasar, A.; Shakshuki, E. Simulation-based Evaluation of Using Variable Speed Limit in Traffic Incidents. Procedia Comput. Sci. 2020, 175, 340-348. [CrossRef]

14. Qiu, F.; Zhang, J.; Li, W.; Zhang, X.; Xie, Q. Exploring suitable traffic conditions for intermittent bus lanes. J. Adv. Transp. 2015, 49, 309-325. [CrossRef]

15. Andersona, P.; Geroliminisb, N. Dynamic lane restrictions on congested arterials. Transp. Res. Part A 2020, 135, 224-243. [CrossRef] 
16. Chiabaut, N.; Xie, X.; Leclercq, L. Improving bus transit in cities with appropriate dynamic lane allocating strategies. Transp. Res. Arena Europe 2012, 48, 1472-1481.

17. Vreeswijk, J.; Armandi, M.; Campello, P. Flexible bus lanes in Bologna. In Proceedings of the 7th European Congress Exhibition Intelligent Transport System Service, Geneva, Switzerland, 4-6 June 2008; pp. 1-10.

18. PTV Vision. User Manual Vissim 5.2; PTV Vision: Karlsruhe, Germany, 2009.

19. Dowling, R.; Skabardonis, A.; Alexiadis, V. Guidelines for Applying Traffic Microsimulation Modeling Software. Traffic Anal. Toolbox 2003, 3 .

20. Dybicz, T. Odwzorowanie fenomenu dwóch przepustowości w mikrosymulacyjnym modelu ruchu w programie Vissim. In Proceedings of the Zeszyty Naukowo-Techniczne Stowarzyszenia Inżynierów i Techników Komunikacji w Krakowie, Kraków, Polska, 12-13 June 2014.

21. Olszewski, P.; Liu, L.; Goh, P. Combined Simulated Annealing and Genetic Algorithm Approach to Bus Network Design. In Proceedings of the International Conference on Transport Systems Telematics, Ustron, Poland, 20-23 October 2010; pp. 335-346.

22. Zhao, L.; Wang, X.; Stoeter, J.; Sun, Y.; Li, H.; Hu, Q.; Li, M. Path Optimization Model for Intra-City Express Delivery in Combination with Subway System and Ground Transportation. Sustainability 2019, 11, 758. [CrossRef]

23. Wang, L.; Zhu, X. Container Loading Optimization in Rail-Truck Intermodal Terminals Considering Energy Consumption. Sustainability 2019, 11, 2383. [CrossRef]

24. Anastasiadis, E.; Angeloudis, P.; Ainalis, D.; Ye, Q.; Hsu, P.-Y.; Karamanis, R.; Escribano Macias, J.; Stettler, M. On the Selection of Charging Facility Locations for EV-Based Ride-Hailing Services: A Computational Case Study. Sustainability 2021, 13, 668.

25. Park, B.; Won, J. Microscopic Simulation Model. Calibration and Validation Handbook; Virginia Department of Transportation: Richmond, VA, USA, 2006.

26. PTV Vision. Introduction to the COM API; PTV Vision: Karlsruhe, Germany, 2015.

27. Michalkiewicz, Z. Genetic Algorithms + Data Structures = Evolution Programs; Springer: Berlin/Heidelberg, Germany, 1996.

28. Osowski, S. Sieci Neuronowe do Przetwarzania Informacji; Oficyna Wydawnicza Politechniki Warszawskiej: Warszawa, Poland, 2006.

29. Dowling, R.; Skabardonis, A.; Alexiadis, V. Traffic Analysis Toolbox_Volume III: Guidelines for Applying Traffic Microsimulation Software; Federal Highway Administration: Washington, DC, USA, 2004.

30. Szarata, M.; Olszewski, P. Traffic modelling with dynamic bus lane. In Proceedings of the 6th International Conference on Models and Technologies for Intelligent Transportation Systems (MT-ITS), Cracow, Poland, 5-7 June 2019.

31. Hea, S.; Dongb, J.; Lianga, S.; Yuana, P. An approach to improve the operational stability of a bus line by adjusting bus speeds on the dedicated bus lanes. Transp. Res. Part. C 2019, 107, 54-69. [CrossRef]

32. Du, Y.; Deng, F.; Liao, F.; Ji, Y. Understanding the distribution characteristics of bus speed based on geocoded data. Transp. Res. Part. C 2017, 82, 337-357. [CrossRef]

33. Szarata, M.; Olszewski, P.; Bichajło, L. Analiza ekonomiczna zastosowania dynamicznie wydzielanych pasów autobusowych. Logistyka 2014, 6 . 